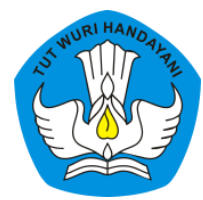

Page: $257-270$

\title{
PENGEMBANGAN MEDIA CROSSWORD PUZZLE BERBASIS HOTS PADA PEMBELAJARAN TEMATIK
}

\author{
Elisabet Dyah Kusuma \\ Sekolah Dasar Negeri Gadingan 02, Mojolaban, Sukoharjo, Jawa Tengah, Indonesia \\ Contributor Email: elisabetkusuma02@gmail.com
}

\begin{abstract}
The development of hots-based Crossword puzzle media in thematic learning aims to improve critical thinking skills in elementary school students, so that there will be an increase in students' critical thinking skills and an increase in student learning outcomes at SD Negeri Gadingan 02, Mojolaban District, Sukoharjo Regency. This innovation is developed by applying research and development methods. The results obtained show that the percentage of student learning outcomes has increased, from before the use of HOTS-Based Crossword Puzzle media was obtained an average of $50.02 \%$, then increased during trial 1 to $56.18 \%$ and increased in trial 2 to $78,75 \%$. The conclusion obtained on the achievement of the increase that occurs due to the use of hots-based Crossword puzzle media, is that the activeness of students in using HOTS-based Crossword puzzle media is a step in increasing critical thinking skills of thematic learning.
\end{abstract}

Keywords: Critical Thinking Skills; Crossword Puzzle; HOTS; Thematic 


\begin{abstract}
Abstrak
Pengembangan media Crossword puzzle berbasis hots pada pembelajaran tematik bertujuan utuk meningkatkan keterampilan berpikir kritis pada siswa sekolah dasar, agar terjadi peningkatan keterampilan berpikir kritis siswa dan peningkatan hasil belajar siswa di SD Negeri Gadingan 02 Kecamatan Mojolaban Kabupaten Sukoharjo. Inovasi ini dikembangkan dengan menerapkan metode penelitian dan pengembangan. Hasil yang diperoleh menunjukan persentase hasil belajar siswa yang mengalami peningkatan, dari sebelum penggunaan media Crossword puzzle berbasis hots diperoleh rata- rata 50,02\%, kemudian mengalami peningkatan saat ujicoba 1 menjadi 56,18\% dan semakin meningkat pada uji coba 2 menjadi 78,75\%. Kesimpulan yang diperoleh atas pencapaian peningkatan yang terjadi dikarenakan penggunaan media Crossword puzzle berbasis HOTS, dimana keaktifan siswa dalam menggunakan media Crossword puzzle berbasis HOTS merupakan tahapan dalam peningkatan keterampilan berpikir kritis pembelajaran tematik.
\end{abstract}

Kata Kunci: Keterampilan Berpikir Kritis; Crossword Puzzle; HOTS; Tematik

\title{
A. Pendahuluan
}

Kurikulum 2013 yang saat ini digunakan merupakan kurikulum pendidikan yang berlaku secara nasional untuk setiap satuan pendidikan. Kurikulum 2013 menekankan pada pembelajaran tematik yang menekankan pada aspek kognitif yakni pengetahuan, afektif yakni sikap dan psikomotorik yakni keterampilan (Daryanto, 2014). Pengembangan ketiga aspek ini dilakukan dalam desain pembelajaran tematik yang harus dirancang guna mempersiapkan siswa menghadapi revolusi industri 4.0 dengan melalui pembelajaran berbasis HOTS. Keterampilan berpikir tingkat tinggi atau High Order Thinking Skill (HOTS) adalah proses berpikir kompleks dalam menguraikan materi, membuat kesimpulan, membangun representasi, menganalisis, dan membangun hubungan dengan melibatkan aktivitas mental siswa yang paling dasar.

HOTS adalah salah satu komponen penting bagi seseorang untuk dapat menyelesaikan masalah baru di abad ke-21 (Brookhart, 2010; Moseley et al., 2005; Thompson, 2008). HOTS juga memainkan peran penting dalam menerapkan, menghubungkan, atau memanipulasi pengetahuan sebelumnya secara berurutan untuk secara efektif menyelesaikan masalah baru (Thomas \& Thorne, 2009). 
Desain pembelajaran tematik berbasis HOTS harus dirancang dengan maksimal agar menghasilkan output yang optimal sesuai tujuan pembelajaran pada khususnya dan tujuan pendidikan pada umumnya dalam pembelajaran yang disajikan. Guru berperan penting sebagai motor penggerak dalam mendesain pembelajaran sedangkan siswa berperan penting pada saat pembelajaran berlangsung karena sebagai subyek pembelajaran. Desain pembelajaran yang dibuat dengan maksimal tentu saja akan menghasilkan output yang optimal pula. Beberapa hasil penelitian menunjukkan bahwa guru perlu untuk mengubah metode pembelajaran tradisional menjadi metode pembelajaran inovatif untuk belajar HOTS. Metode inovatif tersebut adalah pembelajaran yang berpusat pada siswa (Sumarmo \& Nishitani, 2010), penggunaan konstruktivisme, dan pemberian kesempatan kepada siswa untuk mengeksplorasi kemampuan mereka selama kegiatan pemecahan masalah (Apino \& Retnawati, 2017; Djidu \& Jailani, 2016a).

Pembelajaran tematik berbasis HOTS terutama di kelas rendah masih belum dilakukan secara menyeluruh karena sebagian besar guru merasa kesulitan dalam membiasakan siswa untuk berpikir tingkat tinggi. Siswa terbiasa untuk belajar dengan bimbingan guru sepenuhnya bukannya berusaha untuk mengoptimalkan keterampilan berpikir apalagi berpikir kritis dalam pembelajaran. Hal ini terlihat dari fenomena yang terjadi di lapangan bahwa banyak pembelajaran di kelas rendah atau kelas III sekolah dasar yang belum menerapkan pembelajaran tematik berbasis HOTS karena dianggap terlalu susah dan guru kesulitan dalam menumbuhkan minat siswa untuk mau berpikir ke dalam tingkatan yang lebih tinggi.

\section{B. Metode}

Penelitian pengembangan digunakan dalam penelitian ini dengan mengacu pada metode penggunaan model 4-D dengan empat tahap pengembangannya, yakni (1) definisi/ define, (2) perancangan/ design, (3) pengembangan/develop, dan (4) penyebarluasan/disseminate. 
Tahap definisi adalah tahap saat dilakukan analisis dan identifikasi tentang kebutuhan dari masalah dasar yang didapati dan dihadapi pada saat pembelajaran tematik kelas rendah di sekolah dasar. Ketika fokus masalah sudah ditetapkan dalam pembelajaran tematik, peneliti kemudian mengidentifikasi kurikulum, menganalisis karakteristik siswa dan mengidentifikasi serta menganalisis pembelajaran tematik secara lebih dalam. Tahap ini didapatkan sebuah pokok masalah terhadap minimnya pemanfaatan media pembelajaran yang dapat membantu siswa memvisualisasikan konsep abstrak pada pembelajaran tematik dan sebuah pengalaman siswa dalam belajar.

Tahap perancangan adalah tahap kedua yang perancangan menjadi tahap yang merupakan rancangan sebuah media pembelajaran yang dibuat sesuai dengan karakteristik siswa. Media Crossword Puzzle menjadi rancangan untuk digunakan pada pemahaman tematik. Tahap pengembangan adalah tahap ketiga yang mampu menghasilkan sebuah media yang diberi nama Crossword Puzzle, untuk kemudian dilakukan ujicoba pada siswa kelas rendah SD. Tahap penyebarluasan adalah tahap dimana peneliti melakukan penyebarluasan penggunaan media Crossword Puzzle kepada teman-teman sejawat pada gugus yang sama.

Objek Penelitian ini adalah siswa kelas rendah SDN Gadingan 02, sedangkan sampel dalam penelitian ini adalah siswa kelas III SDN Gadingan 02. Instrumen penelitian yang digunakan adalah menggunakan angket, wawancara dan observasi selama proses pembelajaran berlangsung, sedangkan teknik analisis data yang dipergunakan adalah teknik analisis data yang digunakan dalam penelitian ini adalah menggunakan analisis kualitatif interaktif yakni dengan cara pengumpulan data pada penelitian ini dilakukan dengan wawancara dan studi dokumentasi. Reduksi data dilakukan sejak pengumpulan data dengan membuat ringkasan, menulis memo, dan menelusur tema dengan maksud menyisihkan data/informasi yang tidak relevan. Penyajian data dalam penelitian ini dilakukan dengan data kualitatif dalam bentuk teks 
naratif. Simpulan berupa kegiatan interpretasi yaitu menemukan makna data yang telah disajikan.

\section{Hasil dan Pembahasan}

Kurikulum 2013 sebagai kurikulum yang bersifat dinamis merupakan kurikulum yang senantiasa mengalami perubahan sesuai tuntutan paradigma pendidikan masa kini (Daryanto, 2014). Berpikir kritis merupakan salah satu output yang diharapkan dari pembelajaran kurikulum 2013. Pembelajaran yang baik harus dijiwai oleh pembelajaran berbasis HOTS dengan demikian membentuk siswa yang terampil berpikir kritis, pembelajaran yang berbasis HOTS menuntut siswa untuk aktif dan kreatif dalam pembelajaran sehingga guru bersifat sebagai fasilitator maksudnya, guru menjembatani siswa di saat siswa menemukan kesulitan dalam memecahkan masalah yang mereka temukan.

Siswa mampu untuk menciptakan dan memadukan keterampilan ini dalam kegiatan belajar mereka, maka siswa tersebut dapat melakukannya HOT (Rajendran dan Idris, 2008). Smaldino et al, (2004) menyatakan “...rote learning leads to inert knowledge we know something but never apply it to real life". Pembelajar yang memiliki keterampilan berpikir tingkat tinggi (higher order thinking skills) mampu membedakan antara fakta dan opini, mengidentifikasi informasi yang relevan, memecahkan masalah, dan mampu menyimpulkan informasi yang telah dianalisisnya. Tujuan utama dari High Order Thinking Skills adalah meningkatkan kemampuan berpikir peserta didik pada level yang lebih tinggi, terutama yang berkaitan dengan kemampuan untuk berpikir secara kritis dalam menerima berbagai jenis informasi, berpikir kreatif dalam memecahkan suatu masalah menggunakan pengetahuan yang dimiliki serta membuat keputusan dalam situasi-situasi yang kompleks (Cahyana, 2017).

Pembelajaran yang mengoptimalkan keterampilan berpikir kritis siswa berbasis HOTS dapat diimplementasikan dalam tahap-tahap pembelajaran berlangsung melalui media teka-teki silang bergambar atau 
Crossword Puzzle berbasis HOTS. Kegiatan pembelajaran di kelas didesain guru agar dapat menstimulus siswa melalui pemberian teka-teki silang bergambar. Media pembelajaran teka-teki silang bergambar adalah media yang sesuai untuk digunakan dalam pembelajaran tematik. Siswa dapat diberi stimulus dalam pembelajaran melalui gambar-gambar yang disajikan dalam teka-teki tersebut namun Crossword Puzzle pada perkembangannya kurang optimal dalam mengembangkan keterampilan berpikir kritis. Oleh sebab itu peneliti mengembangkannya dengan menggunakan Crossword Puzzle berbasis HOTS. Letak perbedaannya adalah dalam Crossword Puzzle berbasis HOTS menekankan pada stimulus dengan dua gambar yang disertai kalimat sehingga keterampilan berpikir kritis siswa dapat lebih berkembang secara optimal. Media yang sangat menarik sangat mempengaruhi pembelajaran siswa, dengan media pembelajaran yang menarik akan menambah motivasi siswa dalam pembelajaran yang mengarah pada peningkatan keterampilan berpikir secara HOTS.



Gambar 1.2 Crossword Puzzle Berbasis HOTS

Crossword Puzzle berbasis HOTS menekankan pada keterampilan siswa dalam menalar dan berpikir kritis melalui setiap pernyataan yang diberikan lalu menjawabnya dengan jawaban yang tepat, gambar berfungsi untuk lebih memperdalam siswa dalam berpikir. Salah satu gambar berfungsi sebagai pengecoh, dengan demikian siswa akan 
terbiasa menalar apalagi untuk siswa SD kelas rendah (kelas 1-3) masih berpikir secara konkret. Gambar sangat membantu siswa dalam mengoptimalkan proses berpikir dan melatih siswa untuk berpikir kritis.

Cara mengaplikasikan Crossword Puzzle berbasis HOTS dalam pembelajaran tematik yakni (1) Menentukan tema pembelajaran sesuai Crossword Puzzle berbasis HOTS; (2) Membaca setiap petunjuk Crossword Puzzle berbasis HOTS dengan baik; (3) Membaca pernyataan setiap nomor soal baik mendatar atau menurun; (4) Memastikan bahwa jawaban sudah benar dan jawaban masuk dalam setiap tabel/kotak; dan (5) Mengecek kembali jawaban yang dianggap kurang sesuai.

Pengaplikasian media Crossword Puzzle berbasis HOTS sangat menarik dan mudah sehingga keterampilan berpikir kritis siswa dapat lebih optimal karena pembelajaran HOTS dikemas secara lebih sederhana dan menarik. Kelebihan Crossword Puzzle berbasis HOTS ini adalah siswa akan lebih tertarik untuk aktif berpikir kritis secara mandiri, siswa senang karena menggunakan stimulus berupa gambar, kosa kata siswa bertambah, dan siswa belajar dengan cara yang menyenangkan serta menantang sehingga keterampilan berpikir kritis siswa dapat optimal. Crossword Puzzle berbasis HOTS ini dapat diterapkan di kelas rendah (kelas III) sekolah dasar karena disertai gambar sebagai pemicu untuk siswa dapat menjawab setiap kata kunci yang disajikan baik secara mendatar ataupun menurun.

Analisis praktis hasil pengaplikasian inovasi pembelajaran dilaksanakan dengan membandingkan dan melihat perbedaan hasil belajar siswa pada pembelajaran tematik sebelum dan sesudah menggunakan media Crossword Puzzle saat ujicoba 1 dan ujicoba 2. Berikut ini merupakan hasil belajar siswa sebelum memanfaatkan media Crossword Puzzle pada pembelajaran tematik.

Tabel 1

Hasil Belajar Sebelum Menggunakan Crossword Puzzle

\begin{tabular}{cccc} 
No & Banyak Siswa & Nilai yang Diperoleh & Jumlah \\
\hline 1. & 3 & 40 & 80 \\
\hline
\end{tabular}




\begin{tabular}{cccc}
\hline 2. & 1 & 50 & 50 \\
\hline 3. & 2 & 60 & 120 \\
\hline 4. & 1 & 70 & 70 \\
\hline 5. & 1 & 80 & 80 \\
\hline 6. & 1 & 90 & 90 \\
\hline & & Rata-rata & $\mathbf{5 0 , 0 2}$ \\
\hline
\end{tabular}

Tabel di atas menunjukkan hasil belajar siswa pada pembelajaran dengan menggunakan media Crossword Puzzle pada uji coba 1.

Tabel 2: Hasil Belajar setelah Uji Coba 1 Crossword Puzzle

\begin{tabular}{cccc} 
No. & Banyak Siswa & Nilai yang Diperoleh & Jumlah \\
\hline 1. & 2 & 40 & 80 \\
\hline 2. & 2 & 50 & 100 \\
\hline 3. & 1 & 60 & 60 \\
\hline 4. & 1 & 70 & 70 \\
\hline 5. & 2 & 80 & 160 \\
\hline 6. & 1 & 90 & 90 \\
\hline & Rata-rata & & $\mathbf{5 6 , 1 8}$
\end{tabular}

Setelah melakukan beberapa perbaikan pada media Crossword Puzzle atas saran-saran yang masuk, berikut ini adalah hasil belajar siswa menggunakan media Crossword Puzzle pada uji coba2.

Tabel 3: Hasil Belajar setelah Uji Coba 2 Crossword Puzzle

\begin{tabular}{cccc}
\hline No. & Banyak Siswa & Nilai yang Diperoleh & Jumlah \\
\hline 1. & 0 & 40 & 0 \\
\hline 2. & 1 & 50 & 50 \\
\hline 3. & 1 & 60 & 60 \\
\hline 4. & 2 & 70 & 140 \\
\hline 5. & 2 & 80 & 160 \\
\hline 6. & 3 & 90 & 270 \\
\hline \multicolumn{5}{c}{ Rata-rata } \\
\hline
\end{tabular}


Hasil belajar diatas jika dimasukkan dalam perbandingan persentase (\%), tampak terjadi peningkatan yang signifikan. Berdasarkan pra kondisi tanpa menggunakan media hingga ujicoba 1 dan ujicoba 2, aplikasi Crossword Puzzle mengalami peningkatan secara bertahap. Peningkatan yang terjadi karena pelaksanaan pembelajaran dengan memanfaatkan media Crossword Puzzle dalam menyelesaikan soal-soal tematik. Secara utuh, grafik yang menunjukkan perbandingan persentase hasil belajar siswa dapat dilihat pada diagram di atas.

Kesimpulan yang dapat diambil dalam pembelajaran sebelum dan sesudah menggunakan media Crossword Puzzle telah terjadi peningkatan hasil belajar. Ini berarti, penggunaan media Crossword Puzzle terbukti mampu meningkatkan pemahaman konsep tematik yang dapat dilihat dari terjadinya peningkatan hasil belajar siswa. Peningkatan yang terjadi dikarenakan siswa aktif dan berperan langsung dalam memanipulasi media Crossword Puzzle.

Temuan ini sesuai dengan pendapat pendapat Muhsetyo (2007) bahwa penggunaan media gambar mampu menyederhanakan konsep yang sulit kepada konsep yang konkret. Siswa yang melakukan aktivitas manipulatif tergolong dalam tahapan enaktif, yaitu siswa sedang menggunakan pengetahuan motoriknya untuk memahami.

Aktivitas dan kegiatan siswa ketika memanipulasi Crossword Puzzle termasuk dalam proses pemahaman konsep tematik karena semua siswa dapat bebas bereksplorasi setelah menggunakan Crossword Puzzle dengan mengisi jawaban yang benar. Hal itu sesuai pernyataan dari Irawan(2016) tentang penguasaan konsep siswa, bahwa siswa dapat menjelaskan kembali konsep dalam cara dan bentuk berbeda yang lebih mudah dipahami oleh dirinya sendiri. Cara memvisualisasikan hal abstrak tentang konsep tematik yang dilakukan siswa dengan memanfaatkan media Crossword Puzzle sejalan dengan pendapat Piaget (dalam Trianto, 2011) tentang tahapan operasional konkret yang memiliki ciri dengan timbulnya pemikiran siswa yang logis. 
Hasil penelitian ini juga mendukung hasil penelitian terdahulu yang dilakukan oleh Maftakun bahwa media pembelajaran teka teki silang memberikan pengaruh yang signifikan terhadap hasil belajar Bahasa Indonesia siswa kelas IV MI Salamsari. Peningkatan hasil belajar tersebut membuktikan terdapat perbedaan antara hasil belajar Bahasa Indonesia sebelum dan sesudah menggunakan media pembelajaran berbasis android dengan menggunakan teka teki silang. Bedanya, penelitian ini menekankan pengembangan media Crossword Puzzle yang dapat meningkatkan hasil belajar tematik siswa kelas rendah di SDN Gadingan 02.

Selain itu, hasil penelitian ini juga sesuai dengan hasil penelitian yang dilakukan oleh M. Khalilullah yakni penggunaan media teka-teki silang dapat meningkatkan aktivitas guru dan minat belajar siswa sekolah dasar. Penelitian ini ditekankan pada peningkatan hasil belajar yang meningkat setelah menggunakan media Crossword Puzzle berbasis HOTS mampu meningkatkan hasil belajar siswa. Media Crossword Puzzle berbasis HOTS menekankan pada aktivitas pembelajaran yang mengajak siswa untuk mampu berpikir kritis melalui pertanyaan pemancing dalam setiap kata kunci yang diberikan sehingga mampu membuat siswa berpikir secara kritis dan membuat hasil belajar siswa dapat meningkat secara signifikan yang telah dibuktikan dengan penilaian peningkatan hasil belajar siswa.

Penyebarluasan atau diseminasi karya inovasi pembelajaran media Crossword Puzzle dilakukan kepada rekan-rekan guru di SD Negeri Gadingan 02 dan di KKG Gugus I Kecamatan Mojolaban. Melalui diskusi dengan rekan sejawat, Crossword Puzzle diharapkan dapat digandakan, minimal tiap kelas memiliki sendiri agar guru dan siswa di SD Negeri Gadingan 02 dapat lebih bebas menggunakannya. Ketika diseminasi dilakukan dalam lingkup KKG Gugus I Kecamatan Mojolaban, peneliti mendapatkan beberapa saran. Salah satunya adalah terkait penggunaan bahan, Peneliti disarankan untuk menggunakan bahan yang kuat dan awet, 
seperti kertas tebal supaya tidak mudah rusak. Selain itu ada satu hal yang bagus untuk dijadikan rencana perbaikan media Crossword Puzzle ke depannya.

\section{Penutup}

Berdasar pada hasil kegiatan yang telah dilakukan tentang pembelajaran tematik dengan memanfaatkan media Crossword Puzzle, peneliti mengambil kesimpulan bahwa kondisi pembelajaran tematik saat ini terutama di kelas rendah sekolah dasar masih belum optimal karena masih bersifat abstrak dan belum membuat siswa untuk berpikir konkret. Melalui implementasi Kurikulum 2013 pembelajaran tematik diharapkan dapat membuat siswa berpikir konkret sehingga mampu meningkatkan keterampilan berpikir kritis sejak usia dini. Pembelajaran tematik melalui penggunaan dan penerapan media Crossword Puzzle berbasis HOTS di sekolah dasar mampu meningkatkan kemampuan berpikir kritis dan hasil belajar siswa pada pembelajaran tematik yang terlihat dari keaktifan siswa saat memanipulasi media Crossword Puzzle, disamping itu siswa terbantu dan merasakan pengalaman belajar yang menyenangkan dengan menggunakan media Crossword Puzzle.

Atas dasar temuan dan simpulan yang telah dijabarkan sebelumnya, maka saran yang dapat disampaikan adalah (1) Media Crossword Puzzle memiliki fungsi dasar peragaan pada tumbuhnya konsep berpikir siswa yang abstrak. Oleh karena itu, tahapan demi tahapannya perlu dikembangkan agar siswa dapat bereksplorasi hingga mampu melepas konsep tematik tanpa menggunakan media Crossword Puzzle; dan (2) Media Crossword Puzzle hanya dapat digunakan pada kelompok kecil karena masih terbatas.

Diperlukan pengembangan lebih lanjut dengan menambah gambar teka-teki maupun kalimat dan media pemancing teka-teki. Selain itu, kemasan Crossword Puzzle juga dapat disempurnakan agar lebih mudah dan flesibel jika digunakan secara individual. 


\section{Ucapan Terimakasih}

Ucapan terima kasih saya sampaikan kepada Direktorat Pembinaan Guru Pendidikan Dasar, Dirjen Guru dan Tenaga Kependidikan, Kementerian Pendidikan dan Kebudayaan, Dinas Pendidikan Kabupaten Sukoharjo, Kepala Sekolah, dan rekan-rekan guru di SD Negeri Gadingan 02 yang telah membantu dan memberikan kesempatan sehingga peneliti dapat menulis artikel ilmiah ini.

\section{Daftar Referensi}

Ari Irawan \& Chatarina Febriyanto (2016). Penerapan Strategi Pembelajaran Kontekstual untuk Meningkatkan Kemampuan Berpikir Kritis Matematika. Jurnal Ilmu Pendidikan, Jilid 22, Nomor 1, Juni 2016, hlm 9 -17.

Apino, E., \& Retnawati, H. (2017). Developing Instructional Design to Improve Mathematical Higher Order Thinking Skill sof Students.Journal of Physics: Conference Series, 812, 1-7. doi:10.1088/17426596/755/1/011001.

Brookhart, S. M. (2010). How to Assess Higher-Order Thinking Skills in Your Classroom. Alexandria, VA: ASCD.

Daryanto. (2014). Pembelajaran Tematik, Terpadu, Terintegrasi (Kurikulum 2013). Jogjakarta: Gava Media.

Maftakhun. (2020). Pengembangan Media Pembelajaran Teka Teki Silang Berbasis Android pada Mata Pelajaran Bahasa Indonesia. Tesis. Fakultas Tarbiyah. Program Studi Pascasarjana Pendidikan Guru Madrasah Ibtidaiyah. Institut Agama Islam Negeri Salatiga.

M. Khalilullah. Permainan Teka-Teki Silang Sebagai Media Pembelajaran. Jurnal Pemikiran Islam. Vol.37 No.1, Januari 2012, Diakses 11 November 2018.

Rajendran, N., \& Idris, P. U. P. S. (2008). Teaching \& Acquiring Higher-Order Thinking Skills: Theory \& Practice. Penerbit Universiti Pendidikan Sultan Idris.

Smaldino, S. E., Russell, J.D., Heinich, R. \& Molenda, M. 2007. Instructional Technology and Media forLearning. 8th ed. Englewood Cliffs, N.J.: PrenticeHall. Canada. 
Sumarmo, U., \& Nishitani, I. (2010). High Level Mathematical Thinking: Experiment swith High School and Undergraduate Students Using Various Approaches and Strategies. Bulletin of the Faculty of Education, Gunma University, 58 (9), 9-22. Retrieved from https://gair.media.gunmau.ac.jp/dspace/bitstream/10087/5130/1/03_Nishitani.pdf.

Thomas, A., \& Thorne, G. (2009). How to Increase Higher Order Thinking. Retrieved January 2, 2017, from http://www.readingrockets.org/article/howincrease-higher-order-thinking.

Trianto. (2011). Desain Pengembangan Pembelajaran Tematik bagi Siswa Anak Usia Dini TK/RA dan Anak Kelas Awal SD/MI. Jakarta: Kencana Prenada Media Group.

Ucu Cahyana, Abdul Kadir, Monalisa Gherardini (2017). Relasi Kemampuan Berpikir Kritis dalam Kemampuan Literasi Sains pada Siswa Kelas IV Sekolah Dasar. Jurnal Sekolah Dasar, Tahun 26 Nomor 1, Mei 2017, hlm 14-22. 
Vol. 5, No. 1, Maret 2021 